ISSN: $1907-4360$

13

\title{
FAKTOR FAKTOR YANG BERPENGARUH TERHADAP KETERLAMBATAN PADA PROSES PENGADAAN JASA PEMBORONGAN STUDI KASUS : ADB LOAN N0.1798-INO RR(SP
}

\author{
Adhi Purnomo, Harcana Adriantara
}

\begin{abstract}
Abstrak
Penelitian ini dimaksudkan untuk mengantisipasi keterlambatan pelaksanaan proses pengadaan pekerjaan proyek agar tidak terulang di masa yang akan datang dengan cara mengidentifikasi faktor-faktor yang berpengaruh terhadap keterlambatan proyek prasarana jalan. Metode yang digunakan adalah melalukan survei berupa penyebaran kuesioner kepada panitia dan stake holder pengadaan jasa pemborongan pada paket ADB-Loan No. 1789INO. Hasil dari penelitian ini adalah faktor yang berpengaruh terhadap keterlambatan pada proses jasa pemborongan..

Metode pengumpulan data yang dilakukan adalah dengan cara studi literatur dan survey pada sumber informasi yang dibutuhkan berupa wawancara terstruktur dan melalui kuesioner.

Data yang digunakan berupa data primer dan data sekunder. Data tersebut diperoleh dengan cara menyebarkan angket atau kuesioner dengan cara mewawancarai responden secara langsung terhadap pakar dalam bidang yang berkaitan dengan masalah yang dibahas

Berdasarkan pembahasan dari hasil olahan data, temuan dan validasi dapat ditarik kesimpulan bahwa Faktor - faktor yang berpengaruh terhadap keterlambatan pengadaan jasa pemborongan dipengaruhi oleh 2 faktor dominan, yaitu :

Dana pendamping dalam APBN DIPA dana belum siap

Lama waktu yang dibutuhkan untuk mendapatkan ijin/rekomendasi dari Bank

Pembangunan Asia untuk memulai setiap tahapan proses pelelangan
\end{abstract}

Kata kunci : keterlambatan, proses pengadaan

\section{PENDAHULUAN}

Kondisi pelayanan jaringan jalan kepada masyarakat saat ini masih memprihatinkan dan belum optimal. Persentase kerusakan dan kurangnya kapasitas jaringan jalan masih

Adhi Purnomo,ST,MT
Staf Pengajar Jurusan Teknik Sipil
Fakultas Teknik

Universitas Negeri Jakarta, 13220
Harcana Adriantara, MT

Alumnus Jurusan Manajemen Konstruksi Fakultas Teknik Universitas Indonesia

Faktor-faktor yang Berpengaruh terhadap Keterlambatan pada Proses Pengadaan Jasa Pemborongan Studi Kasus : ADB LOAN NO.1798-INO RRSP, 
banyak dijumpai di berbagai daerah. Catatan terakhir kondisi kerusakan jaringan jalan adalah bahwa jalan nasional dengan panjang $26.853 \mathrm{~km} \mathrm{4 \%}$ dalam kondisi rusak ringan dan berat, jalan provinsi dengan panjang $39.745 \mathrm{~km} \mathrm{11 \%} \mathrm{dalam} \mathrm{kondisi} \mathrm{rusak} \mathrm{ringan} \mathrm{dan}$ berat, dan jalan kabupaten dengan panjang 174.669 km 63\% dalam kondisi rusak ringan dan berat, serta jalan kota panjang $26.102 \mathrm{~km} \mathrm{4 \%} \mathrm{dalam} \mathrm{kondisi} \mathrm{rusak} \mathrm{ringan.} \mathrm{Salah} \mathrm{satu}$ alasan utama kerusakan tersebut adalah kurangnya alokasi kebutuhan biaya penanganannya. Ditambah lagi dengan terjadinya krisis ekonomi telah menyebabkan kemampuan penyediaan jasa pelayanan prasarana jalan menurun terutama disebabkan oleh minimnya pendanaan untuk memenuhi kebutuhan operasi dan pemeliharaan prasarana jalan [Direktorat Bintek, 2004].

Pendanaan yang berasal dari pinjaman luar negeri telah banyak dialokasikan untuk kegiatan pembangunan jalan. Peningkatan jumlah pelaksanaan proyek-proyek dengan pinjaman luar negeri dirasakan masih perlu mendapat perhatian khusus. Pinjaman/hibah luar negeri yang telah dimanfaatkan melalui Direktorat Jenderal Prasarana Wilayah ex. Dirjen Bina Marga, sejak tahun 1973 sampai dengan 2002 diperoleh dari berbagai sumber donor. Namun pemberi pinjaman/hibah terbesar untuk membiayai berbagai proyek khususnya pada Direktorat Jenderal Prasarana Wilayah termasuk Jasa Marga adalah Bank Dunia sebesar USD 3.231.000.000, pinjaman Bank Asia sebesar USD 1.556.691.248 dan SDR 18.428.000, dan pinjaman Bank Jepang sebesar JP¥ 701.235.500. Lebih jelasnya dapat dilihat pada tabel berikut :

Tabel 1. Besar dana pinjaman luar negeri Dirjen Bina Marga

\begin{tabular}{|l|l|c|c|}
\hline No & \multicolumn{1}{|c|}{ Proyek } & Bank/Status & Jumlah \\
\hline 1 & Heavy Loaded Road Improvement Project-II & JBIC, Expired & JP¥ 10.240 .000 .000 \\
\hline 2 & Sumatra East Coast Highway Project & JBIC, Ongoing & JP¥ 6.652.000.000 \\
\hline 3 & Road Rehabilitation Sector Project & ADB, Ongoing & USD 190.000 .000 \\
\hline 4 & Sumatra Road Rehabilitation Project & IBRD, Expired & USD 184.000 .000 \\
\hline 5 & East Indonesia Region Transport Project & IBRD, Ongoing & USD 200.000 .000 \\
\hline 6 & North Java Corridor Flyover Project & JBIC, Ongoing & JP¥ 4.287.000.000 \\
\hline
\end{tabular}




\begin{tabular}{|l|l|l|c|}
\hline No & \multicolumn{1}{|c|}{ Proyek } & Bank/Status & Jumlah \\
\hline 7 & .Tanjung Priok Access Road Construction I & JBIC, Ongoing & JP¥ 26.306.000.000 \\
\hline 8 & Tanjung Priok Access Road Construction II & JBIC, Ongoing & JP¥ 26.620.000.000 \\
\hline 9 & $\begin{array}{l}\text { Eighteen Provinces Bridge Rehabilitation } \\
\text { Project }\end{array}$ & JBIC, Expected & JP¥ 27.159.300.000 \\
\hline 10 & Road Rehabilitation Project - II & ADB, Ongoing & USD 150.000 .000 \\
\hline 11 & East Indonesia Region Transport Project-II & IBRD, Ongoing & USD 200.000.000 \\
\hline 12 & Strategic Road Improvement Project & $\begin{array}{l}\text { IBRD, } \\
\text { Expected }\end{array}$ & USD 300.000 .000 \\
\hline
\end{tabular}

Sumber : Departemen Pekerjaan Umum, Direktorat Jenderal Bina Marga, Direktorat Bina Teknik. Juni 1999. Proses Administrasi Penetapan Pemenang Pelelangan Pengadaan Jasa Konsultansi, untuk Pekerjaan Detailed Design and Construction Supervision of SUMEC Under OECF Loan IP-487, pada Proyek Perencanaan Teknik Jalan. Jakarta

Sementara itu, dalam manajemen pengadaan proyek pemerintah memerlukan keseimbangan dalam persyaratan untuk akuntabilitas keuangan efisiensi dan efektivit as), nilai - nilai dasar yang harus diketahui dalam manajemen pengadaan proyek pemerintah keadilan, kebijaksanaan, kejujuran, ketulusan, dll dan tujuan spesifik proyek [Seely, 1997].

ADB LOAN NO. 1798-INO [Directorate General of Highways]

Persetujuan untuk pinjaman ADB No. 1798 untuk pekerjaan Road Rehabilitation Sector telah ditandatangani pada tanggal 27 Maret 2001 antara ADB dengan Pemerintah Indonesia. Dana sebesar 190 juta telah disetujui pada tanggal 11 Desember 2000, diumumkan tanggal 28 September 2001 dan dijadwalkan selesai tanggal 28 Februari 2007. Sasaran proyek adalah mendukung program pemerintah untuk membangun dan meningkatkan kondisi jalan nasional dan propinsi 17 propinsi di Sumatera, Jawa, Kalimantan dan Sulawesi. Proyek ini juga membantu pemerintah untuk menerapkan

Faktor-faktor yang Berpengaruh terhadap Keterlambatan pada Proses Pengadaan Jasa Pemborongan Studi Kasus : ADB LOAN NO.1798-INO RRSP, Adhi Purnomo, Harcana Adriantara 
kebijaksanaan sektor jalan dan meningkatkan kapabilitas PNS di lingkungan Departement Pekerjaan Umum dalam membangun proyek jalan dan jembatan.

Lingkup proyek ini terdiri dari :

1. Pekerjaan jalan dan jembatan dan layanan jasa konsultasi

2. Meningkatkan kapasitas jalan dan jembatan

3. Kebijaksanaan di bidang jalan dan jembatan, dimana kebijaksanaan tersebut diterapkan oleh Direktorat Jendral Bina Marga.

\section{PENGADAAN JASA KONSTRUKSI}

Pengadaan mempunyai pengertian yang luas, namun pengertian moderatnya adalah kegiatan yang dimulai dari perencanaan pengadaan, pemilihan dan pelaksanaan kontrak hingga penyerahan hasil pekerjaan. Pengadaan jasa konstruksi dimaksudkan untuk memilih kontraktor yang sesuai dengan harga, waktu, dan mutu yang telah ditetapkan oleh pemilik proyek. Pengadaan barang / jasa menurut keppres 80/2003 adalah kegiatan pengadaan barang / jasa yang dibiayai dengan dana APBN / APBD, baik yang dilaksanakan secara swakelola maupun penyedia barang / jasa. Prinsip dasar pengadaan jasa konstruksi adalah menerapkan prinsip yang efisien, efektif, terbuka, bersaing, transparan, dan adil serta akuntabel [ Keputusan Presiden No 80/2003, hal 73].

Memilih kontraktor yang terbaik memerlukan satu pengetahuan dan pengalaman yang lebih dari panitia untuk memastikan bahwa kontraktor tersebut secara teknis dan keuangan mampu untuk memenuhi proyek tepat waktu, di dalam anggaran yang ditetapkan [ M. Alsugair, 1999].

Jasa pemborongan adalah layanan pekerjaan pelaksanaan konstruksi atau wujud fisik lainnya yang perencanaan teknis atau spesifikasinya ditetapkan oleh pengguna barang / jasa dan proses serta pelaksanaannya diawasi oleh penggunan barang / jasa [Keputusan Presiden No 80/2003, hal 71].

Dengan memperhatikan nilai - nilai dasar yang ingin dicapai dalam pengadaan proyek pemerintah dan kesulitan dalam melakukan penilaian pengadaan jasa proyek 
pemerintah, maka disusun kebijakkan berupa peraturan dalam melaksanakan pengadaan barang / jasa proyek pemerintah [ Keputusan Presiden No 80/2003, hal 73].

Pemerintah juga mempunyai peran sebagai regulator, peranan yang sangat penting untuk menciptakan lingkungan yang kondusif dengan hukum dan peraturan. Hukum dan peraturan pemerintah perlu mempertimbangkan beberapa hal antara lain [ FIDIC, 2004]:

1. Membuat sasaran kegiatan konstruksi yang spesifik

2. Menciptakan lingkungan konstruksi yang lebih kondusif

3. Melakukan registrasi terhadap personil yang memenuhi syarat dengan profesional sesuai dengan kategorinya

4. Memberikan pengakuan persamaan kualifikasi dan registrasi negara asing FIDIC Policy ini sudah diterapkan dalam peraturan pengadaan proyek pemerintah oleh negara- negara seperti Amerika Serikat Federal Acquisition Regulation, Australia Commenwealth procurement Guidelines, termasuk Indonesia Keputusan Menter i Permukiman dan Prasarana Wilayah No. 257/KPTS/M/2004.

Penerapan peraturan pengadaan pada proyek pemerintah merupakan salah satu bentuk perhatian terhadap penerimaan pajak baik peraturan setempat, hukum perdagangan dan perjanjian internasional [Tipman, 2005]. Fokus strategi pengadaan pemerintah adalah untuk membangun suatu lingkungan kerja yang efektif dimana bersifat responsif dan berhasil mempertemukan tantangan pasar yang meningkat secara kompleks dan kompetitif. Bagi perusahaan, mengurangi ketergantungan pada peraturan yang kaku dan meningkatkan kemampuan dalam pengadaan untuk membangun dan mempraktekkan kemampuan usaha yang baik dalam lingkungan yang menegaskan keseimbangan kompetisi dan kerja sama [ Sherman, 1991]. Peningkatan kompetensi utama dihasilkan dari peningkatan outsourcing dan deregulasi fungsi utama pengadaan dihasilkan dari kompetisi [ Herche, 2004].

Secara umum, hampir semua pekerjaan infrastruktur memerlukan penyedia jasa konstruksi. Jasa konstruksi pada instansi pemerintah bertujuan agar pelaksanaan pekerjaan lebih efektif dan efisien. Pengadaan jasa konstruksi untuk pembangunan

Faktor-faktor yang Berpengaruh terhadap Keterlambatan pada Proses Pengadaan Jasa Pemborongan Studi Kasus : ADB LOAN NO.1798-INO RRSP, Adhi Purnomo, Harcana Adriantara 
prasarana jalan di Indonesia dilakukan berdasarkan Keppres No.80/2003 tentang pedoman pelaksanaan pengadaan barang/jasa pemerintah.

Salah satu butir penting yang perlu dicermati dalam pelaksanaan paket-paket pekerjaan yang mendapat pendanaan dari pinjaman luar Negeri adalah proses pengadaan jasa konstruksi. Proyek dengan dana yang berasal dari pinjaman luar negeri tersebut mempunyai ketentuan pengadaan sesuai ketentuan badan donor terkait yang dapat berbeda dengan ketentuan Keppres. Apabila terjadi perbedaan dan peraturan antara Keppres, peraturan-peraturan lainnya dengan ketentuan dan peraturan dari Donor Bank), maka digunakan ketentuan dan peraturan Bank Donor .

Dalam setiap pengadaan jasa konstruksi untu proyek pemerintah yang didanai dengan pinjaman luar negeri, yaitu Bank Pembangunan Asia Asian Development Bank, ADB sebagai Multi Lateral Agency, maka diatur sistem pengadaan dan penilaiannya dalam Guidelines on the Use of Contractors by Asian Development Bank and Its Borrowers untuk seleksi berdasarkan biaya dan mutu quality and cost based selection, QCBS diperlukan penyampaian proposal teknis dan biaya pada saat yang sama. Proposal yang diterima setelah penutupan waktu penyampaian akan dikembalikan tidak dibuka dan tidak ada perubahan dari proposal teknis dan biaya yang diterima setelah batas waktu.

Proposal teknis yang diterima harus dianalisa secara hati - hati dan dibandingkan terhadap [ADB, 1999]:

1. Pendekatan perencanaan

2. Jadwal pelaksanaan

3. Pengalaman dan kemampuan personil yang ditugaskan

4. Mutu kepemimpinan

5. Kedudukan sebagai pengawas yang akan dilengkapi

6. Perhatian yang diberikan oleh penanggung jawab perusahaan

7. Fasilitas kantor tempat tinggal

8. Bantuan, jika ada, akan tersedia dari pihak lain

9. Pengenalan bahasa dan budaya negara, dimana pekerjaan tersebut akan dilaksanakan, akan dipertimbangkan 


\section{METODA}

Metode pengumpulan data yang dilakukan adalah dengan cara studi literatur dan survey pada sumber informasi yang dibutuhkan berupa wawancara terstruktur dan melalui kuesioner.

Data yang digunakan berupa data primer dan data sekunder. Data tersebut diperoleh dengan cara menyebarkan angket atau kuesioner dengan cara mewawancarai responden secara langsung terhadap pakar dalam bidang yang berkaitan dengan masalah yang dibahas.

\section{HASIL DAN PEMBAHASAN}

Dari pengumpulam data maka diperoleh jenis variabel Variabel $X$, yaitu faktor - faktor yang berpengaruh terhadap keterlambatan proses pengadaan jasa pemborongan yang telah teridentifikasi diperoleh 39 faktor, sedangkan variabel $Y$ adalah waktu. Faktor faktor tersebut dikelompokkan menjadi 4, yaitu:

1. Umum

2. Peraturan

3. Mekanisme Pelelangan

4. Sumber Daya Manusia

Tabel 2. Faktor yang Berpengaruh terhadap Keterlambatan

\begin{tabular}{|l|l|}
\hline & Jenis Variabel \\
\hline & Variabel Terikat \\
\hline Y1 & Kinerja Waktu \\
\hline & Variabel Bebas \\
\hline & A. UMUM \\
\hline X1. & Pengalaman yang kurang sebagai panitia pelelangan \\
\hline X2. & Pemahaman yang kurang pada paket pekerjaan yang dilelangkan \\
\hline X3. & $\begin{array}{l}\text { Pengaruh beban kerja di luar keanggotaan panitia pelelangan sering absen saat } \\
\text { evaluasi tender }\end{array}$ \\
\hline X4. & Intervensi dari luar panitia dalam membuat keputusan pelelangan. Misalnya \\
\hline
\end{tabular}

Faktor-faktor yang Berpengaruh terhadap Keterlambatan pada Proses Pengadaan Jasa Pemborongan Studi Kasus : ADB LOAN NO.1798-INO RRSP, Adhi Purnomo, Harcana Adriantara 


\begin{tabular}{|c|c|}
\hline & Jenis Variabel \\
\hline & organisasi Gapensi, AKI, pejabat setempat, dll \\
\hline $\mathrm{X} 5$. & Dokumen penawaran yang lemah tidak mencakup semua hal dalam kontrak) \\
\hline $\mathrm{X6.}$ & Perubahan Desain rencana saat penyusunan OE dan / atau PQ \\
\hline $\mathrm{X} 7$. & Dana pendamping dalam APBN DIPA belum siap \\
\hline \multirow[t]{2}{*}{$\mathrm{X} 8}$. & Perubahan Harga saat Penyusunan Owner Estimate \\
\hline & B. PERATURAN \\
\hline X9. & Terjadi perubahan pimpinan proyek/struktur organisasi dalam instansi \\
\hline $\mathrm{X} 10$. & $\begin{array}{l}\text { Peraturan-peraturan pelaksanaan dalam proses pengadaan spesifikasi tidak } \\
\text { dipahami }\end{array}$ \\
\hline $\mathrm{X} 11$. & $\begin{array}{l}\text { Adanya Peraturan Pemerintah Daerah yang harus diikuti selain Pedoman Bank } \\
\text { Pembangunan Asia dan Keppres 80/2003 }\end{array}$ \\
\hline $\mathrm{X} 12$. & Kurangnya sosialisasi peraturan dan prosedur pedoman Bank Pembangunan Asia \\
\hline \multirow[t]{2}{*}{$\mathrm{X} 13}$. & Terlalu banyak peraturan yang harus diikuti \\
\hline & C. MEKANISME PELELANGAN \\
\hline $\mathrm{X} 14$. & $\begin{array}{l}\text { Kekurangpahaman pelaksanaan pelelangan terhadap peraturan/prosedur yang } \\
\text { telah ditetapkan Bank Pembangunan Asia }\end{array}$ \\
\hline $\mathrm{X} 15$. & Penyelesaian sanggahan dalam proses pelaksanaan pengadaannya \\
\hline $\mathrm{X} 16$. & $\begin{array}{l}\text { Lamanya waktu yang diperlukan dalam penyusunan dan pendistribusian } \\
\text { Addendum dokumen pelelangan }\end{array}$ \\
\hline $\mathrm{X} 17$. & Lamanya waktu yang diperlukan untuk penyiapan dokumen \\
\hline $\mathrm{X} 18$. & Transparansi informasi setiap tahapan pelelangan bagi peserta \\
\hline $\mathrm{X} 19$. & Kesulitan dalam memahami tata cara evaluasi yang ditetapkan oleh donor ADB \\
\hline $\mathrm{X} 20$. & $\begin{array}{l}\text { Kesulitan mengisi format/bentuk pelaporan hasil evaluasi yang ditetapkan } \\
\text { menurut standar Bank Pembangunan Asia }\end{array}$ \\
\hline $\mathrm{X} 21$. & $\begin{array}{l}\text { Lamanya waktu yang diperlukan untuk proses permohonan persetujuan hasil } \\
\text { evaluasi ke pemimpin proyek/Kepala Satuan Kerja/Satker }\end{array}$ \\
\hline $\mathrm{X} 22$. & $\begin{array}{l}\text { Lamanya waktu yang diperlukan untuk permohonan persetujuan hasil evaluasi ke } \\
\text { Pusat Direktorat Wilayah dan PMU }\end{array}$ \\
\hline $\mathrm{X} 23$ & $\begin{array}{l}\text { Lamanya waktu yang diperlukan untuk permohonan persetujuan hasil evaluasi ke } \\
\text { Bank Pembangunan Asia }\end{array}$ \\
\hline $\mathrm{X} 24$. & $\begin{array}{l}\text { Terbatasnya fasilitas sistem informasi internet yang mengakses informasi bagi } \\
\text { seluruh stakeholder }\end{array}$ \\
\hline $\mathrm{X} 25$. & $\begin{array}{l}\text { Lama waktu yang dibutuhkan untuk mendapatkan ijin/rekomendasi dari Bank } \\
\text { Pembangunan Asia untuk memulai setiap tahapan proses pelelangan }\end{array}$ \\
\hline $\mathrm{X} 26$. & Penilaian saat evaluasi yang samar - samar \\
\hline $\mathrm{X} 27$. & Perencanaan pengadaan yang terburu - buru \\
\hline $\mathrm{X} 28$ & Kolusi saat pengadaan \\
\hline $\mathrm{X} 29$. & Melakukan pengadaan ulangan tanpa alasan jelas \\
\hline $\mathrm{X} 30$. & $\begin{array}{l}\text { Lamanya waktu yang dibutuhkan untuk setiap tahapan penyusunan dan } \\
\text { pendistribusian dokumen }\end{array}$ \\
\hline
\end{tabular}




\begin{tabular}{|l|l|}
\hline & Jenis Variabel \\
\hline & D. SUMBER DAYA MANUSIA \\
\hline X31. & Kemampuan berbahasa Inggris \\
\hline X32. & $\begin{array}{l}\text { Pelatihan yang pernah diikuti tidak banyak menunjang pekerjaan sebagai panitia } \\
\text { pelelangan }\end{array}$ \\
\hline X33. & $\begin{array}{l}\text { Adanya perbedaan pendapat antar anggota panitia dalam memahami } \\
\text { peraturan/prosedur yang ada }\end{array}$ \\
\hline X34. & Kurangnya nara sumber untuk menyelesaikan suatu masalah \\
\hline X35. & Sertifikasi pelelangan yang dimiliki panitia yang kurang \\
\hline X36. & Unsur kehati - hatian panitia \\
\hline X37. & Ketidakhadiran panitia saat perencanaan spesifikasi \\
\hline X38. & Tidak ada wewenang profesional dalam proses pengadaan \\
\hline X39. & Terlambat dalam mengambil keputusan \\
\hline
\end{tabular}

Dari variable-variabel tersebut di analisa menggunakana korelasi. Analisa korelasi pada penelitian ini dilakukan untuk mengukur kekuatan hubungan antara variabel terikat pada Kinerja waktu dengan variabel bebas pada faktor - faktor yang berpengaruh pada keterlambatan. Analisa korelasi dilakukan dengan metode korelasi pearson product moment pearson.

Tabel 3. Nilai Korelasi Pearson r Antara Variabel Bebas terhadap Faktor - Faktor yang Bepengaruh Terhadap Keterlambatan

\begin{tabular}{|c|c|c|c|}
\hline No. & Kode & Variabel & r \\
\hline 1 & $\mathrm{X} 1$ & Pengalaman yang kurang sebagai panitia pelelangan & 0,112 \\
\hline 2 & $\mathrm{X} 2$ & $\begin{array}{l}\text { Pengaruh beban kerja di luar keanggotaan panitia pelelangan } \\
\text { sering absen saat evaluasi tender }\end{array}$ & 0,221 \\
\hline 3 & X3 & $\begin{array}{l}\text { Intervensi dari luar panitia dalam membuat keputusan } \\
\text { pelelangan. Misalnya organisasi Gapensi, AKI, pejabat } \\
\text { setempat, dll }\end{array}$ & 0,295 \\
\hline 4 & $\mathrm{X} 4$ & Perubahan Desain rencana saat penyusunan OE dan / atau PQ & 0,139 \\
\hline 5 & $\mathrm{X} 5$ & Dana pendamping dalam APBN DIPA dana belum siap & 0,459 \\
\hline 6 & $\mathrm{X} 6$ & $\begin{array}{l}\text { Kurangnya sosialisasi peraturan dan prosedur pedoman Bank } \\
\text { Pembangunan Asia }\end{array}$ & 0,010 \\
\hline 7 & $\mathrm{X} 7$ & $\begin{array}{l}\text { Kekurangpahaman pelaksanaan pelelangan terhadap peraturan/ } \\
\text { prosedur yang telah ditetapkan Bank Pembangunan Asia }\end{array}$ & 0,232 \\
\hline
\end{tabular}

Faktor-faktor yang Berpengaruh terhadap Keterlambatan pada Proses Pengadaan Jasa Pemborongan Studi Kasus : ADB LOAN NO.1798-INO RRSP, 


\begin{tabular}{|c|c|c|c|}
\hline No. & Kode & Variabel & $\mathbf{r}$ \\
\hline 8 & X8 & $\begin{array}{l}\text { Lamanya waktu yang diperlukan dalam penyusunan dan } \\
\text { pendistribusian Addendum dokumen pelelangan }\end{array}$ & 0,058 \\
\hline 9 & X9 & $\begin{array}{l}\text { Lamanya waktu yang diperlukan dalam penyusunan dan } \\
\text { pendistribusian Addendum dokumen pelelangan }\end{array}$ & 0,037 \\
\hline 10 & $\mathrm{X} 10$ & Lamanya waktu yang diperlukan untuk penyiapan dokumen & 0,023 \\
\hline 11 & $\mathrm{X} 11$ & $\begin{array}{l}\text { Kesulitan dalam memahami tata cara evaluasi yang ditetapkan } \\
\text { oleh donor ADB }\end{array}$ & 0,275 \\
\hline 12 & $\mathrm{X} 12$ & $\begin{array}{l}\text { Kesulitan mengisi format/bentuk pelaporan hasil evaluasi yang } \\
\text { ditetapkan menurut standar Bank Pembangunan Asia }\end{array}$ & 0,460 \\
\hline 13 & $\mathrm{X} 13$ & $\begin{array}{l}\text { Lamanya waktu yang diperlukan untuk permohonan persetujuan } \\
\text { hasil evaluasi ke Pusat Direktorat Wilayah dan PMU }\end{array}$ & 0,502 \\
\hline 14 & $\mathrm{X} 14$ & $\begin{array}{l}\text { Lamanya waktu yang diperlukan untuk permohonan persetujuan } \\
\text { hasil evaluasi ke Bank Pembangunan Asia }\end{array}$ & 0,372 \\
\hline 15 & $\mathrm{X} 15$ & $\begin{array}{l}\text { Terbatasnya fasilitas sistem informasi internet yang mengakses } \\
\text { informasi bagi seluruh stakeholder }\end{array}$ & 0,206 \\
\hline 16 & $\mathrm{X} 16$ & $\begin{array}{l}\text { Lama waktu yang dibutuhkan untuk mendapatkan } \\
\text { ijin/rekomendasi dari Bank Pembangunan Asia untuk memulai } \\
\text { setiap tahapan proses pelelangan }\end{array}$ & 0,476 \\
\hline 17 & $\mathrm{X} 17$ & $\begin{array}{l}\text { Lamanya waktu yang dibutuhkan untuk setiap tahapan } \\
\text { penyusunan dan pendistribusian dokumen. }\end{array}$ & 0,065 \\
\hline 18 & $\mathrm{X} 18$ & Kemampuan berbahasa Inggris yang kurang & 0,139 \\
\hline 19 & X19 & Kurangnya nara sumber untuk menyelesaikan suatu masalah & 0,430 \\
\hline 20 & $\mathrm{X} 20$ & sertifikasi pelelangan yang dimiliki panitia & 0,240 \\
\hline 21 & $\mathrm{X} 21$ & Unsur kehati - hatian panitia takut melakukan kesalahan & 0,036 \\
\hline 22 & $\mathrm{X} 22$ & Terlambat dalam mengambil keputusan & 0,198 \\
\hline
\end{tabular}

Sumber : Hasil Olahan 
Tabel 4 : Hasil pengolahan data

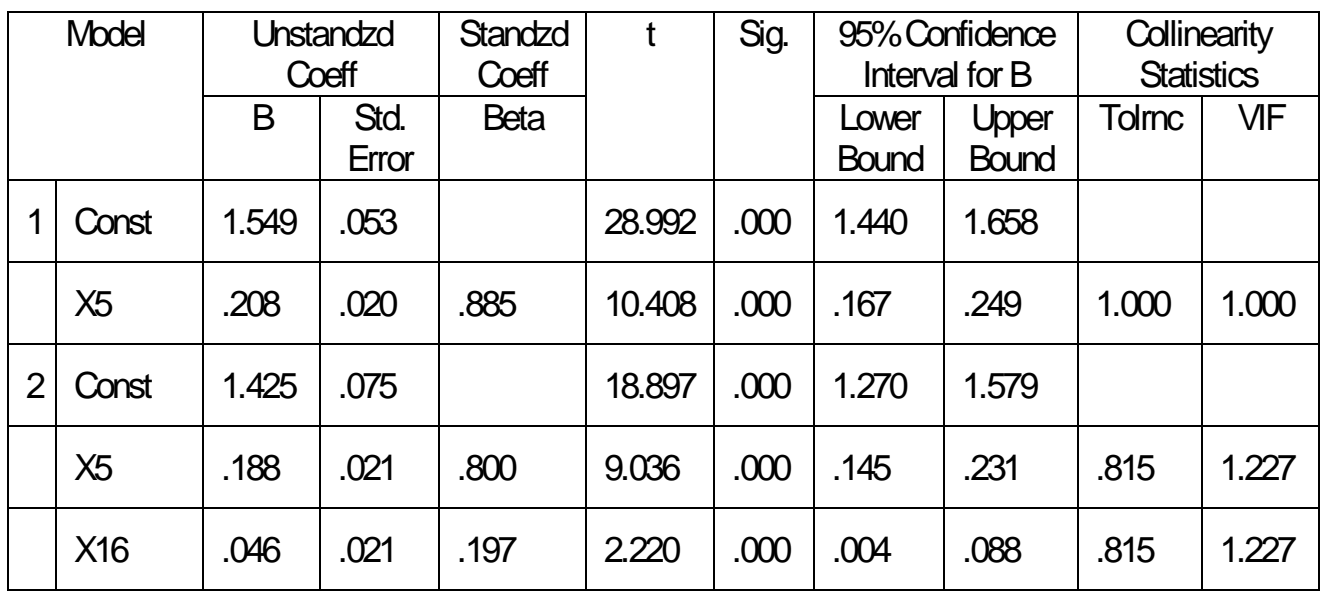

Sumber : Hasil Olahan

Sehingga model yang diperoleh yang merupakan model regresi berganda linier yang mempunyai satu variabel terikat dan 2 variabel bebas definitif dengan koefisien positif sebagai berikut :

$Y=1,425+0,188 X_{5}+0,046 X_{16}$

dengan,

$Y=$ kinerja waktu

$\mathrm{X}_{5}=$ Dana pendamping dalam APBN DIPA dana belum siap

$X_{16}=$ Lama waktu yang dibutuhkan untuk mendapatkan ijin/rekomendasi dari Bank Pembangunan Asia untuk memulai setiap tahapan proses pelelangan

Dari pernyataan model di atas, dapat disimpulkan bahwa model yang diperoleh tersebut telah menunjukkan dari 39 variabel bebas faktor yang telah teridentifikasi menghasilkan 2 variabel bebas yang definitif berpengaruh terhadap variabel terikat $Y$ kinerja waktu. Dapat dikatakan bahwa faktor - faktor yang berpengaruh pada keterlambatan pada proses jasa pemborongan menyebabkan munculnya 2 variabel bebas definitif yang mempengaruhi kinerja waktu.

Faktor-faktor yang Berpengaruh terhadap Keterlambatan pada Proses Pengadaan Jasa Pemborongan Studi Kasus : ADB LOAN NO.1798-INO RRSP, Adhi Purnomo, Harcana Adriantara 


\section{KESIMPULAN}

Berdasarkan pembahasan dari hasil olahan data, temuan dan validasi dapat ditarik kesimpulan bahwa Faktor - faktor yang berpengaruh terhadap keterlambatan pengadaan jasa pemborongan dipengaruhi oleh 2 faktor dominan, yaitu :

- Dana pendamping dalam APBN DIPA dana belum sia $p$

- Lama waktu yang dibutuhkan untuk mendapatkan ijin/rekomendasi dari Bank Pembangunan Asia untuk memulai setiap tahapan proses pelelangan

\section{DAFTAR PUSTAKA}

ADB, November 2001. Project Administration Memorandum Loan No. 1798-INO:RR(SP.

ADB, 1999. Guidelines on the Use of Contractors by Asian Development Bank and Its Borrowers.

Ansori, 2004. "Sumber Resiko Penurunan Kinerja Waktu Pelaksanaan Pekerjaan Konstruksi". PPSBIT. Jakarta.

APCC National Procurement Reform Principles, Australian Procurement and Construction. Council.

Departemen Pekerjaan Umum, Direktorat Jenderal Bina Marga, Direktorat Bina Teknik. Juni 1999. Proses Administrasi Penetapan Pemenang Pelelangan Pengadaan Jasa Konsultansi, untuk Pekerjaan Detailed Design and Construction Supervision of SUMEC Under OECF Loan IP-487, pada Proyek Perencanaan Teknik Jalan. Jakarta.

Direktorat Bintek Direktorat Jenderal Prasarana Wilayah, 2004., Lokakarya Manajemen Proyek ADB Loan 1798-INO, Jakarta.

FIDIC, 2004. Quality of Construction. FIDIC Policy. International Federation of Consulting Engineers, Switzerland.

Herche, J., 2004. Management of Project Procurement, The McGraw-Hill Companies, Inc.

Herche, J., 2004. Management of Project Procurement, The Mcgraw-Hill Companies, Inc.

Keputusan Menteri Permukiman dan Prasarana Wilayah No. 257/KPTS/M/2004 tentang Standar dan Pedoman Pengadaan Jasa Konstruksi Koperasi Bapekin.

Keputusan Presiden No 80/2003 tentang Pedoman Pelaksanaan Pengadaan Barang / Jasa Pemerintah CV. Eka Jaya Jakarta. 
Proposal for Second Extension and Loan Reallocation for ADB Loan No. 1798-INO Directorate General of Highways).

Seely, M \& Duong, Q., 1997. "Measuring Project Procurement management Performance in the Public Sector".

Sherman, SN. Government Procurement Management, Maryland, Wordcrafters Public.

Tipman, M., 2005 “Project and Procurement : What You Don't Know, Can Hurt You. Summit 